\title{
Type 1 diabetes: time to act to raise standards of care
}

\author{
ANNE KILVERT1, CHARLES FOX1', ROBERT GREGORY², PATRICK SHARP³
}

\begin{abstract}
Most people with diabetes are now treated and monitored in primary care, where GPs and practice nurses have become confident in initiating and adjusting insulin. Consequently, the distinction between type 2 and type 1 diabetes has become blurred with the risk that the specialist needs of people with type 1 diabetes may be overlooked. The National Diabetes Audit has demonstrated year on year that people with type 1 diabetes do much worse than their type 2 peers when structured education, care processes, treatment targets and mortality are measured. The paediatricians, faced with similar audit results, have set an example by introducing a Best Practice Tariff (BPT) to raise standards of care for children with diabetes.

The recent publication of 'Type 1 Diabetes Through the Life Span", a position atatement from the American Diabetes Association (ADA), emphasises the specialist needs of people with type 1 diabetes and sets out in detail the standards of care people of all ages should expect. Diabetes organisations in the UK should follow the lead of the ADA by specifying the service requirements which will ensure all people with type 1 diabetes can access the high quality care they need to help them avoid the debilitating complications of their condition.
\end{abstract}

Br J Diabetes Vasc Dis 2014;14:144-147

Key words: type 1 diabetes, standards of care, ADA position statement, National Diabetes Audit

\section{Background}

As our understanding of the causes of diabetes has increased over the years, the classification has been revised: descriptive terms such as 'juvenile-onset' and 'adult-onset', 'insulindependent' and 'non-insulin dependent' have been replaced by 'type 1' and 'type 2 ' diabetes. ${ }^{1}$ This classification, based on

Diabetes Centre, Northampton General Hospital, Northampton, UK

2 Department of Diabetes, University Hospitals of Leicester NHS Trust, Leicester, UK

Southampton General Hospital, Southampton, UK

Address for correspondence: Dr Anne Kilvert

Diabetes Centre, Northampton General Hospital, Cliftonville,

Northampton, NN1 5BD, UK.

Tel: +44 (0)1604 545576

E-mail: anne.kilvert@ngh.nhs.uk

http://dx.doi.org/10.15277/bjdvd.2014.044

\author{
Abbreviations and acronyms \\ $A B C D \quad$ Association of British Clincial Diabetologists \\ ADA American Diabetes Association \\ BPT Best Practice Tariff \\ DSME diabetes self-management education \\ NDA National Diabetes Audit \\ NICE National Institute for Health and Cinical Excellence
}

aetiology, capacity for insulin production and insulin resistance, gets away from the concept that the type of diabetes is defined by age or the need to take insulin, but conveys little to the nonspecialist about the crucial differences between the two types. People with type 1 diabetes report being told by friends/ colleagues that they have diabetes because they have led an unhealthy lifestyle. Many health care professionals do not understand the difference between insulin-treated type 2 diabetes and type 1 diabetes.

As increasing obesity in the general population fuelled a rapid rise in prevalence of type 2 diabetes, a change in the delivery of care was inevitable. Hospital-based diabetes clinics could not possibly cope with the escalating numbers, nor was there any need for them to do so, as primary care was well placed to deliver the treatment and screening required for most people with type 2 diabetes. However, as practice nurses and GPs become more confident in the use of insulin, they do not always distinguish between type 1 and type 2 diabetes. As a result, the specialist needs of people with type 1 diabetes are being overlooked. Good control of type 1 diabetes requires sophisticated insulin regimens, supported by frequent blood glucose monitoring and the latest technology; education must be focused on adapting insulin for a wide variety of life situations. This expertise is beyond the remit of most primary care teams.

\section{National audit data and type 1 diabetes}

The NDA of 8,500 GP practices (87.9\% participation) in 201112 identified more than 2.4 million people with diabetes, of whom approximately 214,000 (8.7\%) had type $1.2,3$ The audit highlighted clear differences between people with type 1 and type 2 diabetes in terms of care processes received, standards of care achieved and access to structured education (Table 1). In all categories people with type 1 diabetes received less care. Mortality was increased by $130 \%$ in people with type 1 diabetes compared with the general population; for type 2 diabetes the increase in mortality was $35 \%$. Most shockingly, young women (age 15-34 years) with type 1 diabetes were seven times more likely to die than their non-diabetic peers. The audit mirrored 
Table 1 National Diabetes Audit 2011-12

Percentage of registered patients receiving eight care processes, achieving treatment targets and offered/ attended structured education

\begin{tabular}{|c|c|c|c|}
\hline & $\begin{array}{l}\text { All } \\
\text { diabetes }\end{array}$ & $\begin{array}{l}\text { Type } 1 \\
\text { diabetes }\end{array}$ & $\begin{array}{l}\text { Type } 2 \\
\text { diabetes }\end{array}$ \\
\hline Eight care processes & 60.5 & 43.2 & 62.6 \\
\hline $\begin{array}{l}\text { Achieving } \\
\text { treatment targets* }\end{array}$ & 20.8 & 11.8 & 21.5 \\
\hline $\begin{array}{l}\text { Offered or } \\
\text { attended structured } \\
\text { education }\end{array}$ & 5.2 & 2.5 & 5.4 \\
\hline
\end{tabular}

that of the previous year, which showed that amongst people with diabetes, those with type 1 were at higher risk of amputations, renal disease and retinopathy. The results prompted the ABCD to launch their 'Lost Tribe' campaign in 2012 (Figure 1). ${ }^{4}$ The campaign aimed to raise awareness of the specialist needs of people with type 1 diabetes, to improve access to specialist services and to increase engagement, particularly of young people, with the specialist services. This has been echoed in the Diabetes Sample Service Specification published online recently by NHS Commissioning. ${ }^{5}$

The National Paediatric Diabetes Audit identified shortcomings in paediatric diabetes care, with poor outcomes compared with European counterparts and no evidence of improvement over a 10-year period. In response to this failure to improve, the BPT for outpatient paediatric diabetes services was introduced in 2012. ${ }^{6}$ A service providing 12 months of care to a young person with diabetes must meet 14 standards to earn the tariff. The initial success of this intervention has led to plans to extend the tariff to include inpatient services and to suggestions that the upper age limit should be increased from 19 to 25 years. In a further initiative, the National Paediatric Diabetes Service Delivery Plan for 2013-18 has been introduced, designed around the needs of children and their families. ${ }^{7}$

Crucial though these measures to improve paediatric diabetes services are, it is important to recognise that people of all ages are living with type 1 diabetes and it is essential to ensure that adults, including older people, also have access to the same high quality diabetes care. It is no longer unusual for people to live with type 1 diabetes for well over 50 years (a duration thought worthy of a medal in the past) and although the peak onset may be in children and young people, type 1 diabetes can develop at any age. ${ }^{8}$ People in their ninth and even tenth decades may now be living with this condition and managing type 1 diabetes in elderly people brings its own challenges. It is time the adult services followed the example of their paediatric colleagues in setting and demanding high standards of care for adults with type 1 diabetes.

\section{'Type 1 Diabetes Through the Life Span'}

The recent position statement from the ADA, 'Type 1 Diabetes
Figure 1. 'Lost Tribe' campaign poster

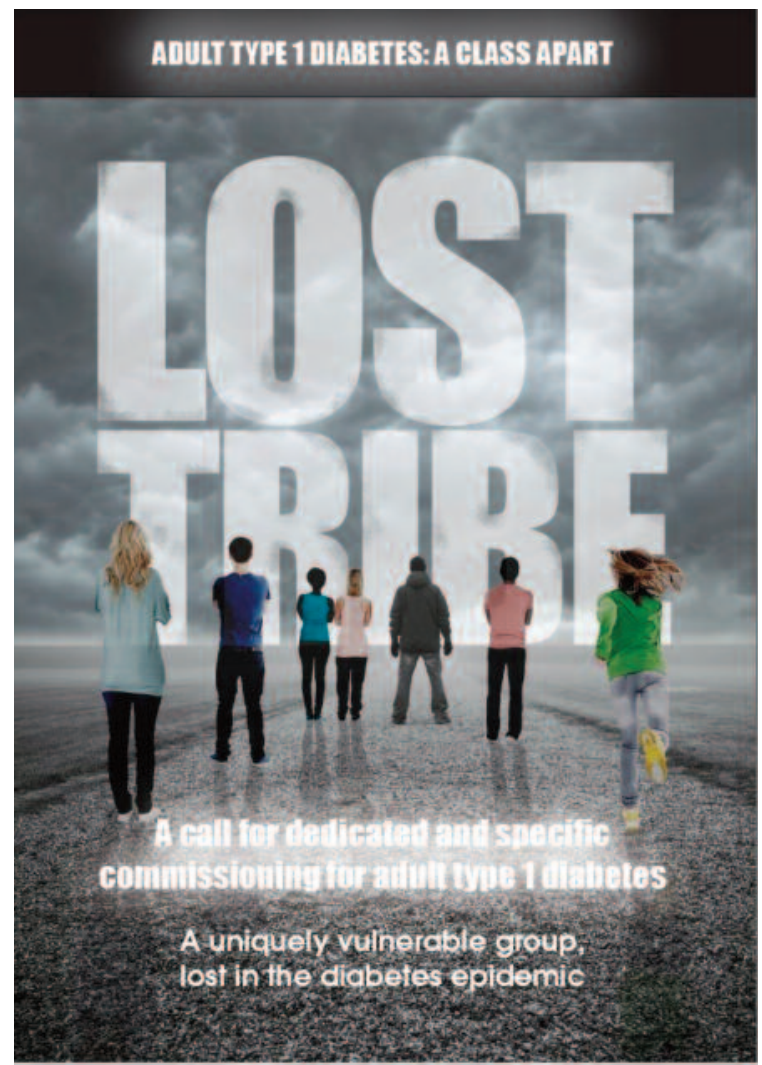

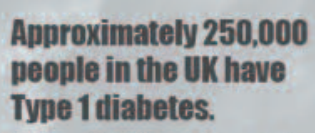

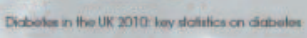

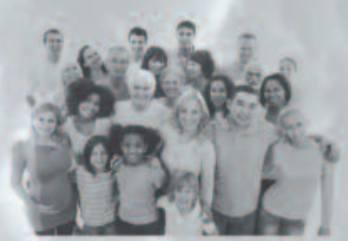

The mortality rate for Type 1 diabetes is 2.6 times higher than the general population.

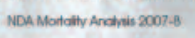

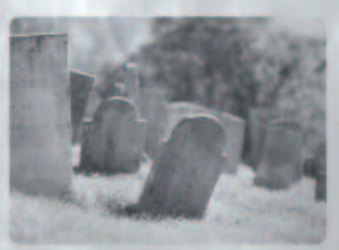

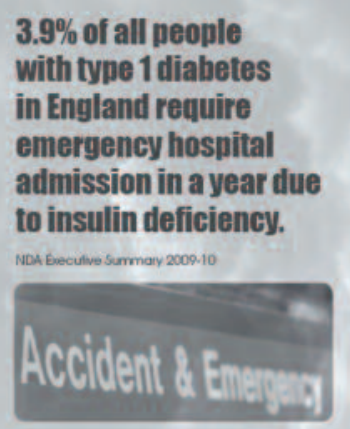

The Gost:

Type 1 diahetes costs the NHS £1.9 billion per year, half of which is spent on treatment of complications.

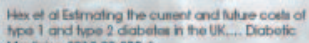
Mbodene 2012:20:855-6

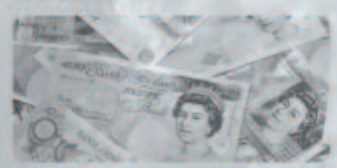


Through the Life Span' recognises the need to focus on type 1 diabetes as a separate entity. ${ }^{9}$ This very detailed document covers all aspects of type 1 diabetes, including classification and diagnosis, education, management and lifestyle advice, treatment targets, psychosocial support, screening for and management of complications, and specific situations such as pregnancy and inpatient procedures. The report identifies seven stages in a patient's lifespan: infancy, play age, school age, adolescence, young adults, middle aged adults and older adults. For each stage, objectives are set for diabetes self-management, education (DSME) and support (DSMS). Responding to inevitable changes in treatment and life circumstances, the report emphasises that 'DSME and DSMS must be a continuous process adapted through the life span of the person with type 1 diabetes so that self-management can be sustained'.

Selected aspects of the position statement are highlighted below.

\section{Healthcare professional support}

The position statement emphasises the crucial role of diabetes specialists in providing the lifelong support required by people with type 1 diabetes. As in the UK, paediatric services usually have the range of professional skills required to provide this support, but the challenge of transitioning from youth to adulthood includes the risk that the supportive infrastructure may disappear. Glycaemic control tends to deteriorate at this time and healthcare providers are advised to agree achievable targets with the young person and their family. These should preserve quality of life while protecting against risk of both hypoglycaemia and complications. Given the initial success of the paediatric BPT, it would make sense to extend it to the 19-25 age-group.

The report recommends that all adults should have access to clinicians with expertise in type 1 diabetes management, including a dietitian and mental health professional. It makes specific recommendations for assessment and treatment of psychosocial issues, nutritional therapy and physical activity. Clinical assessments should be age-focused; a young adult with low cardiovascular risk and no complications may need more assessment of lifestyle adjustment, whereas for an older adult the focus may be on evaluation of vascular and neurological issues. Expectations should be adapted to take into account aging and comorbidities. Glycaemic targets should be age-appropriate with an individualised care plan.

\section{Treatment targets}

While the ADA emphasises the need for individualised targets, taking into account the risk of hypoglycaemia, co-morbidities, life expectancy, frailty etc, the organisation has changed its recommendation for children under 12 and now advises a lower target of $<7.5 \%(58 \mathrm{mmol} / \mathrm{mol})$ across all paediatric age groups. They cite the availability of more sophisticated technology, with potential to improve glycaemic control without hypoglycaemia, and recent evidence for the adverse effect of hyperglycaemia, as opposed to hypoglycaemia, on neurocognitive function in very young children. The recommendation for adults is $<7.0 \%$

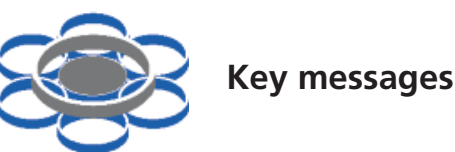

- The National Diabetes Audit has shown that people with type 1 diabetes have significantly less access to care and worse outcomes than those with type 2

- The recently published American Diabetes Association position statement 'Type 1 Diabetes Through the Life Span' sets out the standards of care people of all ages should expect

- UK diabetes organisations must take action to ensure that standards of care are set and achieved for people of all ages with type 1 diabetes

$(53 \mathrm{mmol} / \mathrm{mol})$ where this can be achieved without significant hypoglycaemia. For those in circumstances where less tight control is appropriate a target of $8.5 \%(69 \mathrm{mmol} / \mathrm{mol})$ is advised.

\section{Older adults}

Older people with type 1 diabetes present a difficult challenge. Many will have had years of experience of diabetes and will have worked out a self-management regimen which allows for variable food intake and physical activity. Cognitive decline may impair the ability to make complex self-management decisions and carers are unlikely to be able to take on this role. Given the particular risks of hypoglycaemia in this age group, an individualised approach, with relaxation of targets, is required to maintain the blood glucose within safe limits.

\section{Messages for the UK and a call to action}

The essential theme of the ADA document is that all people with type 1 diabetes should receive specialist input to ensure high quality care throughout their life span. This must adapt to take into account the effect of time and age on individual needs. National standards for service provision, access to support and treatment targets are clearly stated.

In the UK the paediatricians have already taken steps to improve standards and consistency of delivery but, for adults with type 1 diabetes, care remains fragmented and inconsistent. An update to the NICE 2004 type 1 diabetes guideline is expected in August 2015. ${ }^{10}$ Whatever NICE recommends, the UK diabetes organisations must maintain the momentum of the 'Lost Tribe' campaign. They should follow the lead of the ADA by producing a document which defines the service expectations for people with type 1 diabetes, emphasises the need for access to multidisciplinary specialist care and specifies the infrastructure required to underpin it. In doing so they will demonstrate a determination to support people with type 1 diabetes in their daily battle for control of their condition and its potentially lifechanging consequences.

\section{Conflict of interest None \\ Funding sources None}




\section{References}

1. Expert Committee on the Diagnosis and Classification of Diabetes Mellitus. Report of the Expert Committee on the Diagnosis and Classification of Diabetes Mellitus. Diabetes Care 1997;20:1183-97.

2. National Diabetes Audit 2011-12. Report 1: Care processes and treatment targets. http://www.hscic.gov.uk/catalogue/PUB12421/nati-diabaudi-11-12-care-proc-rep.pdf (Accessed September 2014)

3. National Diabetes Audit 2011-12. Report 2: Complications and Mortality. http://www.hscic.gov.uk/catalogue/PUB12738/nati-diab-audi-11-12mort-comp-rep.pdf (Accessed September 2014)

4. Association of British Clinical Diabetologists Type 1 Campaign 2012-13 www.diabetologists-abcd.org.uk/Type1_Campaign.htm (Accessed September 2014)

5. Diabetes Sample Service Specification. NHS Commissioning July 2014. www.commissioningassembly.nhs.uk/pg/cv_content/content/view/1344 33/network (Accessed September 2014)

6. Paediatric diabetes best practice tariff criteria - Diabetes UK February
2012. https://www.diabetes.org.uk/Documents/nhs-diabetes/paediatrics/paediatric-diabetes-best-practice-tariff-criteria-0212.pdf (Accessed September 2014)

7. National Paediatric Diabetes Service Improvement Delivery Plan 2013 18. www.diabetes.org.uk/Documents/nhs-diabetes/paediatrics/National PaediatricDiabetesServicelmprovementDeliveryPlan2013-2018.pdf (Accessed September 2014)

8. Molbak AG, Christau B, Marner B, et al. Incidence of insulin-dependent diabetes mellitus in age groups over 30 years in Denmark. Diabet Med 1994;11:650-5. http://dx.doi.org/10.1111/j.1464-5491.1994.tb00327.x

9. Chiang JL, Kirkman MS, Laffel LMB, et al. Type 1 Diabetes Through the Life Span: A Position Statement of the American Diabetes Association. Diabetes Care 2014;37(7):2034-54.

http://dx.doi.org/10.2337/dc14-1140

10. NICE guideline CG15 July 2004. Type 1 diabetes: Diagnosis and management of type 1 diabetes in children, young people and adults. www.nice.org.uk/Guidance/CG15 (Accessed September 2014)

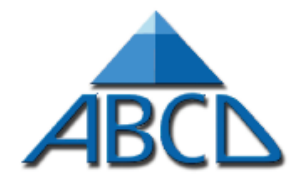

Association of British Clinical Diabetologists

\section{Insulin degludec (Tresiba) Nationwide Audit Now Launched!}

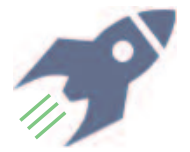

$A B C D$ has launched a nationwide audit of insulin degludec in the UK to assess real clinical efficacy and safety \& inform future practice and guidelines

Does your centre use insulin degludec?

\section{If yes, REGISTER YOUR CENTRE! by contacting degludec.audit@diabetologists.org.uk}

- you are invited to enter your patients' data into the bespoke online tool

- you are able to analyse your local data easily

- the data will be automatically added to the national data in anonymised form

- we can provide easy-to-complete paper proformas for use in clinic if preferred

Please remember: - the more data, the more complete our understanding of insulin degludec in real clinical practice will be

- all contributors will be listed in publications arising from data submission 